\title{
5 Research Square \\ Exploring the Caring Incorporating Yoga Program in Promoting Physical Recovery of Stroke Patients in Acute Phase
}

Kalpana Paudel Aryal ( $\square$ kalpanapaudel1@gmail.com )

Institute of Medicine Nursing Campus Maharajgunj

Urai Hatthakit

Prince of Songkla University

Nongnut Boonyoung

Prince of Songkla University

\section{Research article}

Keywords: Caring, caring incorporating yoga program, physical recovery, Nepal, nurses, stroke in acute phase, yoga.

Posted Date: December 3rd, 2020

DOI: https://doi.org/10.21203/rs.3.rs-28985/v2

License: (9) This work is licensed under a Creative Commons Attribution 4.0 International License. Read Full License 


\section{Abstract}

Background: Caring science integrating cultural practices has become an important health resource to get positive health outcomes for hospitalized acutely ill patients. Yoga, a cultural practice, has the power to bring multiple physical improvements among chronic stroke patients. The purpose of the study is to analyze the experiences of participants by focusing on their roles and perceptions of the power of caring incorporating yoga to promote physical recovery among stroke patients during the acute phase.

Methods: The study is part of an action research entitled "Development of a Caring Model Incorporating Yoga for Promoting Physical Recovery and Wisdom of People Living with Stroke" conducted in a neurology unit of a university hospital in Nepal. Purposeful sample was used to select participants consisting of 16 nurses, 16 stroke patients and their family caregivers. Data was collected using semi-structured interview guidelines and was continued until data saturation. An inductive content analysis approach was used for data analysis.

Results: Three main themes and nine sub-themes emerged from the qualitative data in terms of experiences of the participants of the program. The three main themes were "caring as a tool to establish trusting relationship in acute phase"; "yoga as a practical and powerful tool for physical recovery from stroke during acute phase"; and "perceived physical recovery as a result of the caring incorporating yoga program".

Conclusions: The findings of the study showed that nurses can successfully facilitate early physical recovery of stroke patients using caring incorporating yoga during acute phase. As yoga is well accepted by Hindu stroke patients due to it being culturally congruent with their sociocultural background, it may be effective for physical recovery and healing of the whole person.

\section{Background}

Despite advancement in medical technology and modern medicine in prevention and management of cardiovascular disease, stroke is still the leading cause of death and disability globally, with high incidence and worse prognosis, particularly in developing countries [1], including Nepal [2]. It poses significant effects on a person in terms of physical, functional, psychological, emotional and spiritual health as well as increased economic burden to the society [3]. Therefore, timely and proper management in each phase of stroke is important for getting positive health outcomes [4].

In order to achieve a faster and greater proportion of recovery in stroke patients, rehabilitation interventions should be started soon after the onset of stroke if the patient is medically stable [5]. In acute phase, improving physical function and increasing capability in activities of daily living are the main concerns and needs of stroke patients and their families [6, 7]. In this regard, conventional physical therapies have the main goal of maximizing functional ability $[8,9]$. In contrast, stroke patients also develop extreme levels of negative emotions [10] along with high levels of functional dependency $[11,12]$. They have poor knowledge and understanding about the reality of stroke life [13], lack skill in self-care to overcome the challenges caused by stroke [14], and have poor adjustment to the sense of new life [15], with high caregiving burden in acute phase of the disease and until 3-6 months post stroke [16]. In addition, poorly managed stroke in 
acute stage leads to higher possibility of living with unresolved physical problems and uncertainty that deeply change the client's life in the long term [17]. The abovementioned situations impact negatively in motivation and meaningful participation in rehabilitation intervention and in gaining independence in physical function in terms of activities of daily living, which results in long-term dependency on family members [12]. Many stroke patients experience boredom, disempowerment, frustration, and fatigue while doing conventional physical therapies [8], which may overwhelm the ambition of active independent participation in rehabilitation. Thus, a new model of rehabilitation program can motivate patients to successfully maximize recovery of physical function $[18,19]$.

Lately, basic caring integrating culture has proven to be crucial and worth paying attention to as an important health resource for hospitalized acute and chronically ill patients in maintaining and promoting health. Caring is the main essence of nursing that manifests in nurses' actions and behaviors through building a nurse-patient relationship [20]. Researchers claimed that the concepts of caring and spiritual practice, if paired together, act as a powerful tool that has the potential to create good caring relationship among nurse, patient and patient's family [21]. Through caring relationship, active communication, information [22] and caring atmosphere were created that promote self-care ability, confidence, coping and holistic wellbeing of patients [23], which facilitates healing process even in a critical stage of illness [21, 24, 25].

Yoga is a popular spiritual mind-body practice based on the Hindu tradition [26]. It has become a popular practice for health maintenance and illness recovery in the global community [27] and is a way of life and cultural heritage in Nepal [28]. Yoga has many physical exercises with highly significant positive effect on stroke rehabilitation [29,30], through enhancing neuroplasticity and neural pathways [31] that could enhance functional ability [32]. In addition, it incorporates physical, mental and spiritual elements which have the power to integrate and balance the body, mind and spirit of an individual in various illnesses [33, $34]$ and enhance motivation, positive attitude, and activity participation [35, 32] with high adherence to programs [36], which were lacking in conventional rehabilitation therapies [37]. Therefore, caring incorporating yoga intervention can be a tool to promote physical improvement and ability to do self-care among stroke patients in acute phase. The study aimed to analyze the experiences of participants focusing on their roles and perceptions when participating in caring incorporating yoga to promote physical recovery among stroke patients during the acute phase.

\section{Methods}

\section{Study Design and Settings}

The study is a part of an action research entitled "Development of a Caring Model Incorporating Yoga for Promoting Physical Recovery and Wisdom of People Living with Stroke in Nepal" that will be published later elsewhere. The action research approach allowed an extended period of face-to-face interaction between nurses and patients so that caring incorporating yoga could be successfully implemented. The study was conducted in a university hospital in Nepal. 


\section{Participants}

The participants of the study included purposefully selected 16 registered nurses who were working in neurology ward, having different levels of nursing education and experience, and Hindu by religion (Table 1). Sixteen Hindu stroke patients and their family caregivers participated as associate participants (Table 2). The stroke patients were adults admitted in neurology ward, were cognitively intact as revealed by minimental status examination (MMSE >20) and showed a willingness to participate in the study.

Table 1 Summary characteristics of nurses $(\mathrm{N}=16)$

\begin{tabular}{llc}
\hline \multicolumn{2}{c}{ Characteristics } & Frequency \\
\hline Age in years & $21-30$ & 10 \\
& $31-40$ & 3 \\
\multirow{2}{*}{ Education } & $41-60$ & 3 \\
\multirow{2}{*}{ Position/Designation } & Diploma in Nursing & 3 \\
& Bachelor of Nursing & 13 \\
\multirow{2}{*}{ Work experience in neurology ward } & Nurse supervisor & 1 \\
& Nurse in-charge & 2 \\
& Staff nurse & 13 \\
General training in neurology & $5-10$ years & 10 \\
& Y10 years & 3 \\
Special training in stroke and yoga & Yes & 3 \\
Yoga practice at home & No & 2 \\
& No & 14 \\
& Yes (not regular) & 0 \\
& No & 6 \\
& & 10 \\
\hline
\end{tabular}

Table 2 Summary of characteristics of patients and family caregivers $(\mathrm{N}=32)$

\begin{tabular}{|c|c|c|c|}
\hline \multicolumn{2}{|c|}{ Characteristics } & \multicolumn{2}{|c|}{ Frequency } \\
\hline & & $\begin{array}{l}\text { Patient (n-16) } \\
\text { (n) }\end{array}$ & Family (n-16) \\
\hline \multirow[t]{3}{*}{ Age in years } & $18-40$ & 4 & 10 \\
\hline & $41-60$ & 5 & 6 \\
\hline & $61-80$ & & - \\
\hline \multirow[t]{2}{*}{ Sex } & Male & 9 & 9 \\
\hline & Female & 7 & 7 \\
\hline \multirow[t]{3}{*}{ Education } & Just able to read and write & 7 & 1 \\
\hline & Basic education & 8 & 10 \\
\hline & University education & 1 & 5 \\
\hline \multirow[t]{3}{*}{ Relation with patients } & Spouse (husband/wife) & NA & 5 \\
\hline & Children (son/daughter) & & 9 \\
\hline & Parent (father/mother) & & 2 \\
\hline \multirow[t]{4}{*}{ Habits } & Smoking/tobacco use & 12 & 5 \\
\hline & Alcohol & 8 & 7 \\
\hline & Physical exercise & 7 & 10 \\
\hline & Yoga practice at home & 2 & 3 \\
\hline
\end{tabular}

\section{Ethical Considerations}


The study was approved by Ethical Review Board of Nepal Health Research Council. Administrative permission was taken from the hospital authority. Participants' rights were protected by using written and verbal informed consent for participation, voice recording and use of a camera for capturing some pictures; self-introducing of the researcher; and informing the participants about the purpose of the study and the duration and frequency of the interview. The voluntary nature of participation was clarified to the participants by informing that they could withdraw from the study at any time. Anonymity was assured and participants' privacy and confidentiality maintained throughout the study by not revealing the names or other identifying information of the participants, including during publication.

\section{Program Implementation}

The nurse participants were prepared for program implementation through a training workshop, coaching and daily yoga sessions of 30 minutes per day for four weeks. Afterward, the nurses implemented the program to stroke patients with the help of family caregivers. The whole program was facilitated by the researcher. The program was initiated to the patients from the first day of hospitalization and was continued until discharge (ranged 8-24 days) through active involvement of the nurses, stroke patients and their family members as well as the researcher as a facilitator. After discharge, the program was selfpracticed at home by the patients for 8 weeks with the support of their family caregivers. Therefore, the total length of the intervention program ranged 9-11 weeks. Follow-up of the patients after discharge was done by the researcher through telephone calls at home and by meeting them during clinic visits at the outpatient departments of the hospital. However, the total study period of the whole action research was about one year.

While implementing of the program, firstly, caring relationship was established and maintained between the nurses, patients, and family caregivers by promoting respect, communication, confidence, commitment, and courage in culturally appropriate ways. The enhanced mutual trust and confidence increased motivation and active participation in the program by the patients and family caregivers. The content of the program is given in Table 3 below.

Table 3 Contents of caring incorporating yoga program 
Part-I Essential Part-II Specific Care: Yoga knowledge and practice

Care: Knowledge and skill

1. Overview of knowledge of stroke

1. Overview of Yoga Knowledge

2. Complication prevention and management

3. Discharge reconciliation: medication regimen, point to contact and follow-up clinic visit

2. Components of Yoga:

3. a. Asana (physical exercise): Base poses: Shukshmasana;Pastimomuktasana; Setu Bandasana; Padangusthanana; Utkasana; Utthapaadasana; Savasana

4. Skill on the technique of positioning, transfer, and mobility

b. Yoga Namaste

c. a. Pranayama (breathing exercise): AnulomBilom (alternative nostril breathing); Vastrika (deep inhalation and exhalation)

b. Aum chanting (meditation)

\section{Data Collection}

Data were collected from December 2017 to June 2018 by the first author through a focus group discussion and individual interviews with nurse participants. The first author was the faculty member of the university hospital where the study was conducted. So, she was familiar with the study setting and the participants. Thus, key participants knew the first researcher and supported her throughout the research process. Similarly, she listened to the participants' concerns to understand their views, experiences and social context during the study process. Face-to-face interview was conducted with stroke patients and their family caregivers using open-ended interview guideline with audio recordings that lasted for 20 minutes to one hour for exploring their experiences of using caring incorporating yoga program. To overcome the feeling of hopelessness and the wish to give up the program during the initial period of the intervention, the nurses provided emotional support to the patients and their caregivers by encouraging them to take rests and continuing when they were ready. Fieldnotes were written to document the needed contextual information as well as the researcher's observation of the intervention. Data collection was continued until data saturation.

In addition, Modified Barthel Index (MBI) [38] was used in stroke patients for measuring the score of physical recovery in terms of functional ability of activities of daily living. The ADL score was assessed in four different stages before implementation of the program, i.e., initially, at the time of discharge, at the $4^{\text {th }}$ week and at the $8^{\text {th }}$ week after discharge from the hospital. The MBI scale contains 10 items: feeding, bathing, grooming, bowel control, bladder control, walking, toilet use, transfer, mobility and stairs. In the total score of 100, higher score reflects greater independence while lower score reflects lower independence or higher dependence to perform activities of daily living.

\section{Data Analysis}


Data analysis was started as soon as the data were collected. Inductive content analysis was conducted according to Elo and Kyngas by following the three stages: preparation, organizing, and reporting [39]. In the preparation phase, the entire interview was selected as a unit of analysis. Further, the audio recordings were transcribed verbatim and translated from Nepali language into English by following the steps recommended by van Nes, Abma, Jonsson, and Deeg [40]. The researcher read each transcript several times to immerse into the data and obtain a general sense of data. The researcher conducted open coding, creation of categories and abstraction. In open coding, notes were written in the text while reading the interview transcripts. The written notes were read several times thoroughly, and many headings and codes were written down at the margins to describe all aspects of the content. Afterward, codes were transferred from the margins to coding sheets, and subcategories were classified with a higher level of abstraction. Lastly, relationships between categories were analyzed and linked to expose the structure of the study concepts of physical recovery among stroke survivors.

\section{Rigor of the Study}

Following Lincoln and Guba's [41] criteria of rigor, credibility was maintained through prolonged engagement in the study setting for around one year since the initial phase (reconnaissance) of action research to the end of the study, persistent observation, and peer debriefing through discussion among the research team. In addition, data was triangulated by comparing data from interviews with those from observation and field notes. Collection of "thick" data, use of purposeful sampling technique and detailed explanation of the research process were done to achieve transferability. Dependability was maintained through explaining and documenting the study context, study objectives, and the processes of participant selection, data collection and data analysis. Confirmability was achieved through a detailed description of the research process, by maintaining credibility, transferability, and dependability.

\section{Results}

The results of the study are presented as experiences of the participants in the use of caring integrating yoga to promote physical recovery of stroke patients in the acute phase. The responses are classified into three main themes and nine sub-themes as outlined in table 4. Each sub-theme within a theme is described in detail below with supportive verbatim. Caring as a tool to establish trusting relationship in acute phase The theme reflects the caring work for developing trusting relationship among the nurses, patients and their family members. The supporting sub-themes included 1 ) developing relationship and trust with the patients and their families; 2) gaining knowledge and ability on caring for self and the patients; and 3) perceiving mutual benefits from the program. The nurses felt that they gained trust from the patients and their family members and perceived mutual benefits from the program, which was important for successful implementation of the program with good cooperation from their clients. Similarly, patients and family caregivers developed trust toward the nurses' caring practices because they gained knowledge and skills to take care of the self and the patients and perceived benefits from the program.

\section{Table 4 The main themes and sub-themes}


Themes

Caring as a tool to establish trusting relationship in acute phase

Yoga as a practical and powerful tool for physical recovery from stroke during acute phase

Perceived physical recovery as a result of the caring incorporating yoga program
Sub-themes

Developing relationship and trust with the patients and their families. Gaining knowledge and ability of caring for self and the patients Perceived mutual benefits from the program

Not time-consuming and easy to be implemented

Self-knowing and self-realizing

Creating hope, motivation and will power for recovery in acute phase Feeling comfort, relaxed, refreshed and increased sensation Increased physical exercise and purposeful movements Improvement of self-care ability and ADLs

\section{Developing relationship and trust from the patients and their families}

This sub-theme was expressed by the nurses emphasizing that their caring actions helped in establishing interpersonal relationship and in gaining trust from the patients and their family caregivers. Trust is a basic quality required to facilitate patient and family engagement in caring during hospitalization. Initially many nurses admitted that communication with the clients in acute phase was difficult due to patients' lost voice, denial and feeling shocked due to their being at maximum level of stress and anxiety. However, active communication was intentionally created in each moment and at every encounter while interacting with the patients and their families through verbal and non-verbal means such as direct interactions, listening, touching, silent presence, eye-to-eye contact, and attention. Establishing relationship and trust was supported by verbatims given by the participants during hospitalization. A senior staff nurse stated:

Before using this program, I never thought about interaction with patients as a part of care. But now we are often talking with patients. I am enjoying talking with them while providing care. I listen to them, pay attention to them, make eye contact, and touch them. These interpersonal techniques are very effective in developing understanding and trusting relationships. (N-5)

Similarly, an in-charge nurse also perceived benefits of relationship and trust while providing care during the program. She stated:

Because of a trusting relationship, they showed co-operation and active participation while implementing the program. They responded to us promptly while meeting, wanted to share their happiness by showing 
their success by smiling at us, sitting on a chair, walking, greeting, speaking and so forth. I found them happy and cheerful. (N-1)

The nurses also mentioned that the patients and family members were being closer with the nurses like family members. Such relationship resulted in developing self-motivation and active participation in their own care.

\section{Gaining knowledge and ability in caring for self and the patients}

This sub-theme emerged from the experiences of the nurses, patients and their family caregivers after implementation of the program. Educating the stroke patients in their acute stage of illness while urging them to practice, it was challenging. They often were initially seen as not physically-mentally ready to learn new things due to sudden loss of muscle movement along with psychological disturbance. Provision of appropriate set of yoga practice through caring approach with genuine attention, understanding the physical limitation of the patients, encouraging, motivating, and presence of a nurse and family caregiver were used successfully in the study. In turn, such caring actions of the nurses helped to cheer up and motivate the patients as well as their family caregivers to continue self-working for patients' recovery. They gained both knowledge about the disease and ability to self-care after having stroke. The statement is supported by the verbatim given by a young female stroke patient during hospitalization:

Sisters give me information and teach me how to do yoga. Now I understand about my disease and what to do for my recovery. I am trying to sit for a long time rather than lying on the bed all the time. I also practice some yoga poses while seated and lying. (P-4)

The young son of a female stroke patient shared his experiences as he gained knowledge and skill for caring his mother before discharge from the hospital:

A sister taught me about the technique of transfer, walking and so on. Most importantly, you taught us about yoga. We've got a chance to learning new things. Now I am able to provide care to my mom. As a result, we achieved an early improvement in my mom. (F-3)

Important strategies linked with caring that encouraged patients to actively participate in the program were

being motivated, being confident and having hope to get recovery. A senior nurse mentioned her experience to support the above statement as follows:

They (patients) repeat the same activity many times accordingly without feeling bored. They presented more motivation and hope to get cured. Patients also follow our instruction easily. This may be because we implement this program only in cognitively intact patients who are not severe. Our nurses pay attention and care to them using this program. $(\mathrm{N}-16)$

\section{Gaining mutual benefits from the program}

The program was aimed at bringing expected health outcomes for the patients. After implementing the program, the nurses also experienced several of their own benefits and changes from the program. Nurse 
participants often reflected that the program helped them understand their crucial role in patients' recovery, that their caring actions significantly changed their perception toward nurses' professional role and practice. As a result, it helped to uplift the nursing profession as well as bring satisfaction and pride with their changed role in the care. The supportive verbatims are presented as follows:

After being involved in the program, I feel that nurses play a vital role in patient's rehabilitation and early recovery. Before this program, we just performed routine works and sat down at the station. I had never felt satisfied like this before. (N-6)

A nurse in-charge also shared her experience about the benefits of the program:

Basically, we want positive health outcomes of the patients which are gained from the program, such as early transfer, early limb movement, walking, speech. Such positive outcomes directly help to increase our job satisfaction. Therefore, this program is good for us, but it is far better for the stroke patients for their early recovery. $(\mathrm{N}-1)$

Caring work as a tool for establishing trusting relationship among nurses, patients and their family, thus, influenced stroke patients to practice yoga actively for their physical recovery.

\section{Yoga as a practical and powerful tool for physical recovery of stroke during acute phase}

In this study, yoga was used to help in physical recovery of stroke patients in acute phase. The yoga methods used were yoga asana to rehabilitate and strengthen muscles and pranayama (breathing exercise) and aum chanting to calm down the mind and boost up the spirit, which resulted in increased selfawareness and motivation in self-work toward expected physical recovery. Three supporting sub-themes were 1) not time consuming and easy to be implemented;2) self-knowing and self-realizing; and 3) creating hope, motivation and will power for recovery in acute phase.

\section{Not time consuming and easy to be implemented}

This sub-theme reflects that yoga was practical and possible for stroke patients in the acute phase in real clinical practice. The majority of the nurses compared, with happy and cheerful faces, their own perception before and after implementation of the program. The sub-theme reflects the confidence, willingness and attention of the nurse participants toward the program. Supportive verbatim by a staff nurse is as follows:

Now we have just the opposite thought to that we had before about using the program and yoga to the stroke patients. The yoga exercise is very simple, and easy to practice and implement to acute stroke clients. Stroke patients are using it without any difficulties. We teach them only once and they consciously follow every pose properly. Afterwards, we just observe whether they can do them properly or not. (N-7)

An in-charge nurse shared her experience:

In fact, in the beginning of the program, we were scared that it might increase our workload and make routines more complex. In reality, it was easily applied. Patients and their family caregivers took initiation themselves after we taught. Then, it did not put an extra load on us but made it easy. (N-2) 
Most nurse participants expressed the main reasons for accepting yoga as being easy to practice and not time consuming to teach the patients even in acute phase of stroke. Since yoga belongs to Hindu culture, the nurses were familiar to it and perceived it as good for health, and some had prior experience. A senior staff nurse who is familiar with the benefits of yoga for health shared the reason for accepting yoga easily by participants:

Actually, in Nepal, most of the people are familiar with the term yoga and know well about its benefits, and had heard the term yoga in their day-to-day life. Therefore, they feel it easy to practice. This booklet also helps to understand it clearly. (N-3)

The wife (school teacher) of a stroke patient who was taking care of her husband during the program for 3 weeks in the hospital also had similar perception:

When a new patient was admitted, sisters responded promptly and taught yoga exercise immediately, which I observed here when caring for my husband. Maybe due to Hindu culture, doing yoga and chanting aum became possible, which we knew from our childhood. (F-13)

Other reason for adopting yoga by stroke patients was the variety of techniques that suited conditions of the stroke patients in acute stage, such as yoga asana, pranayama, and chanting aum that exist in the program. Yoga asana also has different types of physical activities suitable for stroke patients in acute phase, ranging from very gentle to those requiring rigorous movements.

\section{Self-knowing and self-realizing}

Self-knowing and self-realizing experienced by the stroke patients after continued practice of yoga were described as knowing the current health condition and surrounding environmental and social factors as they really are, and realizing the changes and self-responsibility of care for recovery. The development of self-knowing and self-realizing of the stroke participants helped them to participate in the program actively, which resulted in early recovery of physical function, as reflected in verbatims. An in-charge nurse in the hospital expressed her experience as follows:

After 2-3 days of practicing yoga, patients and family caregivers not only felt but also realized their own role and responsibility in patient's care. That's why they participated actively in their own care from their side. ( $N$ 1)

A patient spoke about his improvement after practicing yoga for seven days in the hospital as follows:

After practicing yoga, I found improvement in my voice and in the ability to move my weak leg and walk with support. I have confidence that I can follow the program as guided in the booklet. I feel that I will be better soon. (P-15)

\section{Creating hope, motivation and will power for recovery in acute phase}

Due to sudden onset of disease, patients had lost hope and will power. The program gave motivation to them, which impacted on their participation and consequently their recovery, as reflected by verbatims. A 
patient who had practiced yoga since her childhood shared her experience after 10 days of program implementation:

Yoga is the thing that I was doing previously since my childhood. Now, I felt confident that I would get well, with the feeling that now nothing untoward will happen to me, that I can do yoga. I've got more courage to do other activities. (P-5)

Additionally, after two to three days of participation in the program in the hospital, stroke patients noticed a prompt but subtle change in their physical body that acted as a good facilitator resulting in increased will power, hope, motivation and self-confidence. This is supported by verbatims given by nurses.

Regarding feeling of improvement in the acute stage of the patient, only a small notable change can play a vital role in creating hope and will power toward recovery and improvement. For instance, when patients can offer namaste by using the disabled hand with the support of the good hand, they may feel some achievement in independence. (N-6)

As I observed in my night duty, a patient started to chant aum since early morning and also at nighttime until she felt asleep. Her vocal improved very fast. Since that time, I extremely believe that aum chanting can bring vocal improvement faster. (N-12)

The above description of all themes shows the effectiveness of caring incorporating yoga that acted as a powerful tool in patients' recovery. Ultimately, the program enhanced the physical recovery in many ways.

\section{Perceived physical recovery as a result of the caring incorporating yoga intervention}

The theme is reflected in narratives given by the stroke patients and family caregivers, complemented by the scores of activities of daily living. The findings showed that meaning of recovery and purpose in life after stroke varied from person to person. The three supporting sub-themes were feeling comfort, relaxed, refreshed and increased sensation; increased physical exercise and purposeful movements; and improvement of self-care ability and ADLs, which are described below.

\section{Feeling comfort, relaxed, refreshed and increased sensation}

While asking about their perception about the program in terms of physical health condition, most of the stroke patients felt comfortable, refreshed, relaxed and increased sensation on the paralyzed side after participation in the program. Nurses and family caregivers also shared the same perception with the patients. The statement is supported by following verbatims expressed by a male patient on the 8th day of program implementation:

I am able to do all the exercises as mentioned in the book. I feel more relaxed and refreshed in my body. Although I cannot move my right hand at all on its own, I can move it with the support of my left hand. Today, I was able to raise up my hands fully while doing yoga namaste. I'm feeling better. (P-11)

Similarly, a family caregiver also expressed her feeling of physical recovery of the stroke participants after a week of hospitalization. She stated: 
My husband had not been able to move his right hand and to feel touch, hot, cold or pain in his right hand and leg. It was totally frozen when we arrived in the hospital. But now, after coming to hospital and doing yoga practice, his sensation came back. (F-14)

\section{Increased physical exercise and purposeful movements}

After stroke, almost all patients were immobile and spent their time on bed. In contrast, after initiation of the program, they gained independence in doing some previous tasks such as offering namaste using both hands, moving fingers, and chanting aum. The resuming of previous tasks led to development of positive attitudes and motivation toward care participation, recovery and future life. A senior staff nurse expressed it as follows:

I observed that patients looked excited to move their hands, chanted aum and offered namaste to others, and family members encouraged and helped them in practicing. Several patients kept on moving their limbs. This may be because of independent practice and perceived improvement in health. Anyway, all those exercises enhanced physical recovery of the patients. (N-5)

The above improvement and perception toward the program may have enhanced the improvement in selfcare ability and level of independence in activities of daily living.

\section{Improvement in self-care ability and ADLs}

Improvement in self-care ability and activities of daily living were reflected in narrative expression of the nurses and patients and in ADL scores.

A female stroke patient with a moderate stroke shared, on the 5th day of practicing yoga in the hospital, about her improvement in activities of daily living as follows:

At the beginning, I laid on bed for 2-3 days in the hospital. I had a pipe for urine and another for feeding. Now, I can go to the toilet, can brush and eat by myself. I need little support for wearing clothes, combing hair, walking and going to the toilet. My daughter helps me for these. But I can clean my hand, wash face, and brush my teeth myself. I know that the program has made a great impact on gaining such improvement. (P-9)

A senior nurse remarked that a patient's physical recovery after 10 days of hospitalization was partly due to caring actions that motivated continuing self-practice of the stroke patients:

Do you know the patient in bed number 56, a young boy? In the first 2-3 days of hospitalization, he was sleeping all the time, aphasic, weak, sad and depressed. His condition was very critical. He was partially dependent. After I taught him some yoga practice along with continuous communication, counseling, and encouragement, he was motivated. Now, he can move around, can speak some words, and can eat with partial support. I felt that our encouragement and concern played a vital role in the recovery of this patient, who hadn't shown interest in the beginning but gradually became motivated and now can follow us. (N-3) 
Physical recovery of the stroke participants was confirmed by the ADLs scores. The ADLs scores were assessed at four different stages by using Modified Barthel Index Scale (MBI) [38]. The findings show that the initial ADLs score ranged 15-55. Out of 16 patients, 6 patients scored below 20, whereas the remaining 10 scored 21-60. It indicates that all the patients needed support from others for doing ADLs in acute phase. However, on the day of discharge (8-24 days), 9 patients were still in the stage of severe dependence (scored 21-60), whereas 6 patients were in moderate dependence (scored 61-90). Only one patient was in fully independence (scored 100). At the end of the program (9-11 weeks), half of the patients were in slight dependence or independence (scored above 90), whereas half of them were in moderate dependence (scored 60-90). The ADLs scores helped confirm the perceived health outcomes as a result of the program implementation; that is, the caring incorporating yoga program was useful and contributed to physical recovery of stroke patients in acute phase.

\section{Discussion}

The findings of the study revealed the uniqueness of caring incorporating yoga program that resulted in early physical recovery of Nepali Hindu stroke patients in acute phase, as perceived by the nurses as well as by the patients themselves and their family caregivers. The perceived physical recovery in a positive manner shows the effectiveness of the program that was culturally congruent with the sociocultural background of the participants, as all of them were Hindu by religion. The findings show that the patients appeared to accept this program very easily.

Three main themes with nine interrelated sub-themes, as reflected by the nurses, patients and family caregivers, emerged from their experiences in participating the program toward the patients' expected health outcomes. The themes included caring as a tool to establish relationship and trust in acute phase; yoga as a practical and powerful tool for physical recovery from stroke during acute phase; and physical recovery as a result of the caring incorporating yoga program.

Caring incorporating yoga was focused on physical recovery through caring approach, and the yoga methods selected to use in this study were yoga asana, yoga namaste, pranayama and aum chanting. While yoga asana and namaste were targeted at recovery of physical body [42], pranayama and aum chanting were primarily used for working on the mind or psychospiritual aspect $[43,44,45]$. Mental wellbeing was also included as a goal of the program intervention because body and mind closely influence each other in health. Therefore, the stability of psychological, emotional and spiritual health of the patients amplifies the progression of physical health as well as holistic health.

The practice of pranayama and aum chanting helped to cultivate mindfulness that brought self-awareness and self-realization, and further led to realization of new health condition and meaning of life, which was an important motivation and driving force to continue self-practice following the program. Caring helped to stimulate active engagement of the patients and family into the care. In the present study, caring incorporating yoga attracted more attention from the patients due to the synergic effect of caring and yoga. It was evident that the patients easily accepted the program and continued to practice it due to several reasons, such as close support and guidance by nurses, being acquainted with and having faith in yoga, 
ability to practice in free time, easy availability and affordability and having varieties of yoga methods to select to suit the condition of stroke patients, as well as experience of some positive health outcomes in a short period of time, such as voice, transfer from bed, and movement of hands. The acceptance and continuing practice of the program can be considered as success factors of the program.

A trusted relationship based on understanding and respect gained from the stroke patients and their families was paramount in enhancing the capacity of the stroke patients to self-care for their recovery. It was reported that a good nurse-client relationship is crucial to help the clients meet their healthcare needs [46], optimize the sense of recovery [24, 47], and harmonize body-mind-spirit [21] for stroke patients. In the present study, caring was initially overlooked by the nurses in the clinical practice. Their attitude toward nursing-caring began to be shaped by the trainings provided and their experiential caring practice following the program. The nurse participants have learnt that the caring incorporating yoga was easy, practical and did not burden their workload as they had previously thought. Instead, caring could be rewarding and fulfilling [48]. The nurses felt proud and satisfied by the positive responses and health outcomes of the patients as well as the uplift of the nursing profession, which was also reported by previous studies [21, 24, 25]. Therefore, caring is the central concept of nursing which also facilitates to establish relationship and trust that resulted in capacity to self-care, and finally achieve expected health outcomes in the patients in acute phase.

Furthermore, the study also revealed that yoga acted as a powerful and practical tool for physical recovery from stroke during acute phase. Yoga was easy, practical and powerful for Hindu stroke patients to practice for their physical recovery. The practice of pranayama and meditation by chanting aum helped cultivate mindfulness that allowed the patients to understand and realize their illnesses and the important role they had in stroke recovery. Yoga practice also helped to create hope, motivation and will power for recovery, primarily based on their self-practice. These changes occurred from within as a result of yoga practice, complemented by encouragement from nurses through caring approach to continue the practice of yoga. Previous studies revealed that pranayama and chanting aum are good for dealing the motivation [36] and for connection of body and mind as well as for overcoming fatigue and hopelessness [42]. Additionally, it was reported that self-compassion and greater mindfulness were found among acute ill patients who practice yoga for 6 weeks [49]. Change in the patients' insight was crucial for their initiation to work for their own health improvement.

This article does not aim to prove the effects of the caring incorporating yoga program, but rather to explore experiences and perceptions of the nurses, patients, and their caregivers regarding health outcomes as a result of participating in the program. Although successful health outcomes have been experienced, these positive outcomes cannot be totally attributed to the program because it was studied in a natural setting. There are many factors that may have contributed to the recovery, such as age, type of stroke, size and location of lesion, and comorbidities [11,50]. In the present study, the age of the patients ranged 28-80 years, where more than half of them were under 60 years. All the patients were cognitively intact and had good support from their families, so they could understand and follow the instructions of the nurses and health care providers accordingly. Existing studies reveal that lack of physical activities and having complications in early stage are associated with poor functional outcomes [51,52]. Thus, application of 
yoga intervention at the early stage of stroke may have a greater impact on physical function. Studies revealed that around 50 percent of the recovery occur during the first 2 weeks and 48 to 91 percent of the recovery within three months after disease onset [53]. In the present study, the program was initiated from the second day of hospitalization among medically stable and cognitively intact stroke patients in acute stage.

The present study presented the power of caring and yoga in improving physical recovery as well as in improving holistic health of stroke patients in acute phase. The success factors of the program are the trusted relationship gained from the patients and the easy, practical and effective yoga methods that well suited the patients' health conditions. The findings will serve as a guideline to nurses in caring practice integrating yoga to their stroke patients in the acute phase and help patients to regain their sudden loss of physical function due to stroke.

\section{Conclusions}

The findings of the study reveal a new empirical knowledge in nursing practice: that caring incorporating yoga contributes to early recovery among stroke patients in the acute phase, as perceived by health care professionals, patients, and their family caregivers. This study might encourage nurses to realize and give attention to the observation that caring nurse-patient relationship is essential for improving the health outcomes as well as for the nursing profession. Nurses in clinical setting can use this knowledge to improve their nursing care to the critical patients in the hospital as well as after discharge for rehabilitation. Such type of knowledge can be replicated in the global community with patients having a different clinical illness. Therefore, this study suggests nurses to support, motivate and encourage patients with stroke in acute phase by creating a conducive learning and practicing environment for yoga practice to enhance physical function and others dimension of health for wellbeing. Moreover, based on this study, nurses can focus on clinical control trial studies in the future to identify the effectiveness of yoga practice for optimizing healing of stroke in acute phase.

\section{Abbreviations}

MBI: Modified Barthel Index; ADLs: Activities of Daily Living

\section{Declarations}

\section{Ethics approval and consent to participate}

This study was approved by Ethical Review Board of Nepal Health Research Council in Dec. 2017 (Reg. no, 471/2017). Before data collection, a written consent was obtained from all participants after they were informed of the purpose of the study and the voluntary nature of their participation.

\section{Acknowledgments}


The authors would like to express special thanks to the authority of the university hospital of Nepal for granting us permission to conduct this study. The authors would like to acknowledge the participants for their valuable participation, time and contribution in the study. The authors also express their sincere thanks to Thailand's Education Hub for ASEAN Countries (TEH-AC) Scholarship for providing financial support for the study.

\section{Availability of data and materials}

The datasets generated and analyzed during the current study are available by contacting the corresponding author.

\section{Consent for publication}

Not applicable.

\section{Authors' contributions}

KPA led the study; KPA and UH contributed in study design; KPA collected the data; KPA and UH analyzed and interpreted the findings. KPA and UH wrote the first draft of the paper, and all authors revised the draft and approved the version for submission.

\section{Funding}

The authors received financial through Thailand's Education Hub for ASEAN Countries (TEH-AC) Scholarship.

\section{Competing interests}

The authors declare that they are no competing interests.

\section{References}

1. Feigin VL, Norrving B, Mensah GA. Global burden of stroke. Circ. Res. 2017;120(3):439-48.

2. Thapa A, Bidur KC, Shakya B, Yadav DK, Lama K, Shrestha R. Changing epidemiology of stroke in Nepalese population. NJNS. 2018;15(1):10-8.

3. Lui SK, Nguyen MH. Elderly stroke rehabilitation: Overcoming the complications and its associated challenges. Curr Gerontol Geriatr Res. 2018;2018(9853837):1-9. Available from: https://doi.org/10.1155/2018/9853837.

4. Cameron JI, Naglie G, Gignac MA, Bayley M, Warner G, Green T, et al. Randomized clinical trial of the timing it right stroke family support program: Research protocol. BMC Health Serv. Res. 2014;14(1):18.

5. National Stroke Association. Rehabilitation therapy after a stroke. 2019. Available from: https://www.stroke.org/.

6. English C, Healy GN, Coates A, Lewis LK, Olds T, Bernhardt J. Sitting time and physical activity after stroke: Physical ability is only part of the story. Top Stroke Rehabil. 2016;23(1):36-42. 
7. Krishnan S, Pappadis MR, Weller SC, Fisher SR, Hay CC, Reistetter TA. Patient-centered mobility outcome preferences according to individuals with stroke and caregivers: A qualitative analysis. Disabil. Rehabil. 2018;40(12):1401-9.

8. Luker J, Murray C, Lynch E, Bernhardsson S, Shannon M, Bernhardt J. Carers' experiences, needs, and preferences during in-patient stroke rehabilitation: A systematic review of qualitative studies. Arch Phys Med Rehabil. 2017;98(9):1852-62.

9. Satink T, Cup EHC, de Swart B. JM., \& Nijhuis-van der Sanden MWG. How is self-management perceived by community living people after a stroke? A focus group study. Rehabil. 2015;37(3):223-30.

10. Crowe C, Coen RF, Kidd N, Hevey D, Cooney J, Harbison J. A qualitative study of the experience of psychological distress post-stroke. J. Health Psychol. 2016;21(11):2572-79.

11. Gajurel BP. A Descriptive Study on Ischemic Stroke. NJNS. 2014;11(1):26-9.

12. Parikh S, Parekh S, Vaghela N. Impact of stroke on quality of life and functional independence. Natl J Physiol Pharm Pharmacol. 2018;8(12):1595-98.

13. Taule T, Strand LI, Skouen JS, Raheim M. Striving for a life worth living: Stroke survivors' experiences of home rehabilitation. Scand J. Caring Sci. 2015;29(4):651-61.

14. Makela P, Gawned S, Jones F. Starting early: Integration of self-management support into an acute stroke service. BMJ Open Qual. 2014;3(1):1-7.

15. Connolly TC. Post-stroke survivors' experiences of the first four weeks during the transition directly home from the hospital [dissertation]. Boston College, William F. Connell School of Nursing, 2014. Available from: https://search.proquest.com.

16. Bimali I. Understanding the burden of caring people for clients with a stroke in the subacute and chronic phase in Nepal. Int. J. Curr. Res. Rev. 2015;7(11):39-43. Available from: http://www.ijcrr.com/uploads/528_pdf.pdf.

17. Simeone S, Coehn MZ, Savini S, Pucciarelli G, Alvaro R, Vellone E. The lived experiences of stroke caregivers three months after discharge of patients from rehabilitation hospitals. Prof. Inferm. 2016;69(2):103-12. DOI: 10.7429/pi.2016.692103.

18. Eames S, Hoffmann T, Worrall L, Read S, \& Wong A. Randomised controlled trial of an education and support package for stroke patients and their carers. BMJ Open. 2013;3(5):e002538.

19. Gillespie DC, Bowen A, Chung CS, Cockburn J, Knapp P, \& Pollock A. Rehabilitation for post-stroke cognitive impairment: An overview of recommendations arising from systematic reviews of current evidence. Clin Rehabil. 2015;29(2):120-128.

20. Adams LY. The conundrum of caring in nursing. Int. J. Caring Sci. 2016;9(1):1-8. Available from: http://internationaljournalofcaringsciences.org/docs/1_1-Adams_special_9_1.pdf.

21. Ismail S, Hatthakit U, Songwathana P. Exploring Islamic based caring practice in intensive care unit: $A$ qualitative study. Nurse Media J. Nurs. 2018;7(2):91-100.

22. Pajnkihar M, Stiglic G, Vrbnjak D. The concept of Watson's carative factors in nursing and their (dis) harmony with patient satisfaction. Peer J. 2017;5:1-16. DOI 10.7717/peerj.2940. 
23. Sit JW, Chan AW, So WK, Chan CW, Chan AW, Cha HY, et al. Promoting holistic well-being in chronic stroke patients through leisure art based creative engagement. Rehabilitation Nurs. 2014. Available from: https://doi.org/10.1002/rnj.177.

24. Mardiyono M. Effect of the nursing-based intervention integrating Islamic relaxation on anxiety and perceived control [doctoral dissertation]. Faculty of Nursing, Prince of Songkla University, Thailand. 2012. Available from: http://kb.psu.ac.th:8080/psukb/bitstream/2010/8749/1/362590.pdf.

25. Papathanasiou I, Sklavou M, Kourkouta L. Holistic nursing care: theories and perspectives. J. Nurs. Sci. 2013;2(1):1-5.

26. Bower JE, Greendale G, Crosswell AD, Garet D, Sternlieb B, Ganz PA, Irwin MR, Olmstead R, Arevalo J, Cole SW. Yoga reduces inflammatory signaling in fatigued breast cancer survivors: A randomized controlled trial. Psychoneuroendocrinology. 2014;43:20-9.

27. McCall MC, Ward A, Roberts NW, Heneghan C. Overview of systematic reviews: Yoga as a therapeutic intervention for adults with acute and chronic health conditions. Based Complementary Altern. Med. 2013;(1):1-18.

28. Kumar VR, Aanand S. Yoga: A case of reverse Innovation. Purashartha - A journal of Management, Ethics and Spirituality. 2015;8(2):12-8.

29. Lawrence M, Junior FT, Matozinho HH, Govan L, Booth J, Beecher J. Yoga for stroke rehabilitation. Cochrane Database of Systematic Reviews. 2017;(12).

30. Shah SH, Engelhardt R, Ovbiagele B. Patterns of complementary and alternative medicine use among United States stroke survivors. Journal of the Neurological Sciences. 2008;271(1-2):180-5.

31. Ekusheva EV, Damulin IV. Post-stroke rehabilitation: Importance of neuroplasticity and sensorimotor integration processes. Neurosci Behav Physiol. 2015;45(5):594-9.

32. Van Puymbroeck M, Allsop J, Miller KK, Schmid AA. ICF-based improvements in body structures and function, and activity and participation in chronic stroke following a yoga-based intervention. Am. J. Recreat. Ther. 2014;13(3):23-33.

33. Bayley-Veloso R, Salmon PG. Yoga in clinical practice. Mindfulness. 2016;7(2):308-19.

34. Sengupta P. Health impacts of yoga and pranayama: A state-of-the-art review. Int. J. Prev. Med. 2012;3 (7):444-58.

35. Mahmoud S, Elaziz NAA. Impact of stroke on life satisfaction and psychological adjustment among stroke patients during rehabilitation. Life Sci J. 2016;13(3):7-17.

36. Hogan BE. 1st Place: The effectiveness of yoga therapy on an adult, post-stroke population, a systematic review. 2016. Available from:

https://digitalcommons.chapman.edu/undergraduateresearchprize/11/.

37. Morris JH, Oliver T, Kroll T, Joice S, Williams B. Physical activity participation in community dwelling stroke survivors: Synergy and dissonance between motivation and capability. A qualitative study. Physiotherapy. 2017;103(3):311-21.

38. Shah S, Vanclay F, Cooper B. Improving the sensitivity of the Barthel Index for stroke rehabilitation. J. Clin. Epidemiol. 1989;42(8):703-9. 
39. Elo S, Kyngas H. The qualitative content analysis process. J. Adv. Nurs. 2008; 62(1):107-15.

40. VanNes F, Abma T, Jonsson H, Deeg D. Language differences in qualitative research: Is meaning lost in translation? Eur J Ageing. 2010;7(4):313-16.

41. Lincoln YS, Guba EG. Criteria for assessing naturalistic inquiries as reports. Beverly Hills, CA: Sage Publications; 1988.

42. Schmid AA. Puymbroeck MV. Yoga therapy for stroke: A handbook for yoga therapists and healthcare professionals. London and Philadelphia: Singing Dragon; 2019.

43. Bullock BG. How does yoga work? The study sheds light on mechanisms of change. 2016. Available from: https://www.yogauonline.com/.

44. Saraswati SS, Stevenson J. Yoga and Samkhya: Purifying the elements of the human being. 2017. Available from: https://www.yogajournal.com.

45. Yogitha B, Ebnezar J. Can yoga be an effective tool in managing psychological stress? AJ Ethno. 2014;1:1-7.

46. Kitson AL, Dow C, Calabrese JD, Locock L, Athlin AM. Stroke survivors' experiences of the fundamentals of care: A qualitative analysis. Int. J. Nurs. Stud. 2013;50(3):392-403.

47. Campinha-Bacote J. A biblically based model of cultural competence in the delivery of healthcare services: Seeing “Imago Dei”. 2nd ed. Cincinnati, OH: Transcultural C.A.R.E. Associates; 2013.

48. Jasemi M, Valizadeh L, Zamanzadeh V, Keogh B. A Concept analysis of holistic care by hybrid model. Indian J. Palliat. Care. 2017;23(1):71-80.

49. Toise SC, Sears SF, Schoenfeld MH, Blitzer ML, Marieb MA, Drury JH, et al. Psychosocial and cardiac outcomes of yoga for ICD patients: A randomized clinical control trial. PACE. 2014;37(1):48-62.

50. Carod-Artal FJ, Lanchipa JO, Ramírez LM, Pérez NS, Aguayo FM, Moreno IG, et al. Stroke subtypes and comorbidity among ischemic stroke patients in Brasilia and Cuenca: A Brazilian-Spanish cross-cultural study. J Stroke Cerbrovasc Dis. 2014;23(1):140-47.

51. Bustamante A, Garcia-Berrocoso T, Rodriguez N, Llombart V, Ribo M, Molina C, Montaner J. Ischemic stroke outcome: A review of the influence of post-stroke complications within the different scenarios of stroke care. J. Intern. Med. 2016;1(29):9-21.

52. Wong JS. Falls post-stroke: A setback on the road to recovery? [doctoral dissertation]. Rehabilitation Sciences Institute University of Toronto. 2015. Available from: https://tspace.library.utoronto.ca/bitstream/1807/70700/1/Wong_Jennifer_S_201511_MSc_thesis.pdf.

53. Lee KB, Lim SH, Kim KH, Kim KJ, Kim YR, Chang WN, et al. Six-month functional recovery of stroke patients: A multi-time-point study. Int J Rehabil Res. 2015;38(2):173-80. 